\title{
Antibacterial Behavior of Laser-Ablated Copper Nanoparticles
}

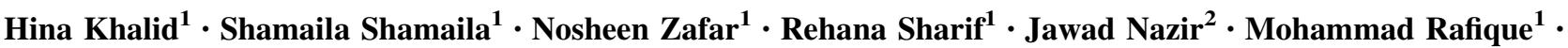 \\ Sheeba Ghani ${ }^{1} \cdot$ Hussain Saba ${ }^{1}$
}

Received: 19 December 2015/Revised: 23 April 2016/Published online: 27 June 2016

(c) The Chinese Society for Metals and Springer-Verlag Berlin Heidelberg 2016

\begin{abstract}
Copper nanoparticles (Cu NPs) have been synthesized by using laser ablation method, using deionized water as main solvent. The formation of Cu NPs is confirmed by UV-visible spectrophotometer (UV-Vis), atomic force microscopy (AFM) and X-ray diffraction (XRD). Cu NPs fabricated by laser ablation have diameter in the range from 14 to $55 \mathrm{~nm}$. Structural analysis revealed the face-centered cubic (fcc) crystal structure of $\mathrm{Cu}$ NPs. The antibacterial activity of Cu NPs has been evaluated in vitro against strains of Escherichia coli (E. coli) and Staphylococcus aureus (S. aureus). The fabricated $\mathrm{Cu}$ NPs show considerable antibacterial activity against both bacterial strains. The bacterial activity of Cu NPs was found to depend on the microbial species.
\end{abstract}

KEY WORDS: Laser-ablated nanoparticles; UV-visible spectrophotometer; Atomic force microscopy (AFM); Escherichia coli; Staphylococcus aureus

\section{Introduction}

Nanoparticles are fascinating materials, which have been applied widely in fields of basic and applied research. Copper nanoparticles (Cu NPs) with high fraction of surface atoms and high specific surface area have been widely studied. The $\mathrm{Cu}$ NPs have special physical and chemical characteristics, which include catalytic activity, antimicrobial activity, optical properties and electronic properties [1]. Cu NPs can be fabricated by using different physical and chemical techniques, such as chemical reduction [2-4], laser ablation [5, 6], electrochemical [4], thermal

Available online at http://link.springer.com/journal/40195

Hina Khalid

hina.khalid189@gmail.com

1 Department of Physics, University of Engineering and Technology, Lahore 54890, Pakistan

2 Department of Microbiology, University of Veterinary and Animal Sciences, Lahore, Pakistan decomposition [7] and polyol method [8]. Laser ablation synthesis in solution (LASiS), as a different approach for the synthesis of metallic nanoparticles, appeared in last few years. It is possible to attain a good control on dimension of nanoparticles by using laser method and appropriate liquid environment [9]. For nanoparticle generation, large number of laser sources can be used, e.g., $\mathrm{Cu}$ vapor laser, $\mathrm{Nd}$ :YAG laser and its harmonics $[5,10]$ and continuous laser (diodepumped solid-state laser) [11]. Many factors affect the fabrication of nanoparticles, such as type of laser, pulse duration, number of pulses, laser energy and type of solvent. The researchers have used various liquid environments, such as deionized (DI) water [12], polysiloxane, pure acetone [12], sodium dodecyl sulfate (SDS) and polyvinylpyrrolidone (PVP) for fabrication of colloidal solution of metallic nanoparticles (nanofluids). The size and dimensions of metallic nanoparticles are similar to the most of biological structures and molecules. This makes the nanoparticles be an interesting candidate in biomedical research for both in vivo and in vitro applications [13]. So, a confluence of biology and nanotechnology can address many biomedical problems and revolutionize the fields of 
dentistry and health [14]. Currently, noble metal nanoparticles have been extensively studied and are well known for their antimicrobial effects. For nanoparticles synthesis, the noble metals, such as silver and gold, are being used, despite their cost $[1,13,15]$.

Silver and $\mathrm{Cu}$ NPs exhibit strong antimicrobial activity. Sliver-containing materials can be used in vascular grafts, to reduce infection, as dental materials as well as to inhibit the bacterial colonization [16]. Gold nanoparticles are used for drug delivery purposes [17, 18]. Metallic nanoparticles play a crucial role in inhibiting the growth of bacteria in solid and aqueous media due to their large surface-to-volume ratio. Metallic nanoparticles and nano-sized carriers for drug delivery prove their effectiveness for treating infectious diseases in vitro as well as in animal models [15]. Nobel metallic nanoparticles are more appropriate, but in the literature, there is no significant report on antibacterial activity of pure Cu NPs by turbidity method. Studies of Russel et al. [19] on the antibacterial properties of copper and silver were reported. In this context, copper is a good alternative material because it is more economical than silver and gold.

In the current research, the attention has been focused on the fabrication and biomedical applications of $\mathrm{Cu}$ NPs. Nanoparticles are synthesized by laser ablation of bulk copper in liquid environment. The $\mathrm{Cu}$ NPs were characterized by using different techniques, such as UV-visible spectrometry, atomic force microscopy (AFM) and X-ray diffraction (XRD). The antibacterial activities of $\mathrm{Cu}$ NPs were used to study against human pathogenic bacterias of E. coli and S. aureus.

\section{Experimental Method}

\subsection{Synthesis of Cu NPs by Laser Ablation}

Experimental setup for fabrication of $\mathrm{Cu}$ NPs by laser in liquid environment is simple. A metallic copper target with purity of $99.9 \%$ and $15 \mathrm{~mm}$ in thickness was first rinsed with ethanol and then several times with distilled water to remove surface contaminations. The cleaned target was placed under a thin layer of liquid. Through this layer, the target was exposed to laser radiations. Deionized water was used as a liquid environment for laser ablation. A pulsed Nd:YAG laser with the wavelength of $1064 \mathrm{~nm}$, pulse length of $10 \mathrm{~ns}$ and energy of $10 \mathrm{~mJ} /$ pulse was used for the copper target ablation. The laser was operated at a repetition rate of $10 \mathrm{~Hz}, 1000$ and 1500 shots fall on the target. Laser irradiation on target surface $(\mathrm{Cu})$ resulted in fast removal of the material from the confined laser spot. The produced $\mathrm{Cu}$ NPs remained in liquid. This liquid with nanoparticles is called colloidal solution. Schematic representation for fabrication of $\mathrm{Cu}$ NPs by laser ablation (Nd:YAG) is shown in Fig. 1.

\subsection{Antimicrobial Assays}

There are a variety of methods, such as well diffusion method [20], micro-dilution method [21], serial dilution method [22] and turbidity method [23], to investigate the antimicrobial activity of metallic nanoparticles against the microorganism. In the present study, an indirect turbidity method was used to check the antimicrobial activity of $\mathrm{Cu}$ NPs against two human pathogenic gram-negative bacteria Escherichia coli (E. coli) and gram-positive bacteria Staphylococcus aureus (S. aureus) to calculate the concentration of minimum inhibition. The diameter of inhibition zone was further measured by well diffusion method.

The turbidity method was characterized by a series of test tubes that contain different concentrations of doses (nanoparticles), in a culture medium inoculated with test microorganism [23]. An aliquot of fresh culture of E. coli and $S$. aureus was transferred to a test tube containing $5 \mathrm{ml}$ nutrient broth medium and incubated at $37{ }^{\circ} \mathrm{C}$ for $24 \mathrm{~h}$ for the bacterial cultures. The suspensions obtained from this growth were used as the inoculums. After $24 \mathrm{~h}$ of incubation, the optical density of broth media and inoculums was measured by spectrophotometer, which was used to calculate the percentage growth of E. coli and $S$. aureus. The growth of E. coli and S. aureus was 82.2 and $82.8 \%$, respectively, after $24 \mathrm{~h}$.

Each set was inoculated with $200 \mu \mathrm{l}$ of the respective bacterial suspension. Three concentrations of Cu NPs were prepared for testing $(19,39$ and $58 \mu \mathrm{mol} / \mathrm{l}$ labeled as low, medium and high doses, respectively) against $E$. coli and $S$. aureus. In order to avoid contaminations, all of the work was performed in the sterilized area (around the flame of Bunsen burner). A negative control (only $\mathrm{Cu} \mathrm{NPs}$ ) and a positive control (only bacteria) were also used. The inoculated sets have incubated for $24 \mathrm{~h}$ at $37{ }^{\circ} \mathrm{C}$. All experiments for antibacterial activity have been performed in

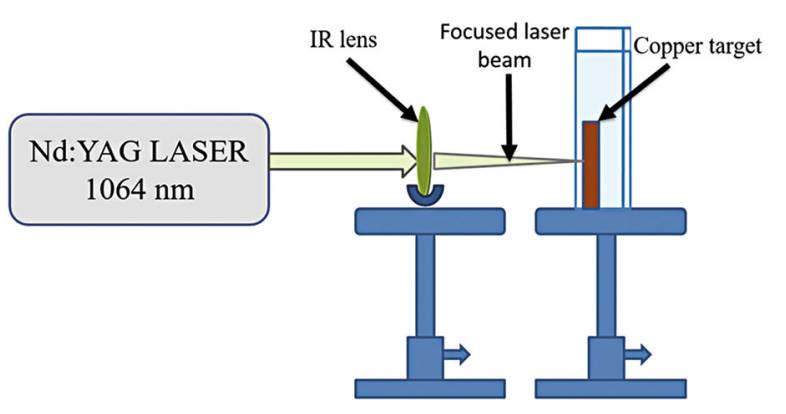

Fig. 1 Schematic representation of $\mathrm{Cu}$ NPs synthesized in deionized water by LASiS 
triplicate. After that time, the presence or absence of bacteria (turbidity) is determined by optical density (OD) measurements by spectrophotometer at $600 \mathrm{~nm}$.

To calculate the diameter of inhibition zone, well diffusion technique was employed. The nutrient plates of agar were geared up with four wells. The solution of bacterial culture of $S$. aureus and E. coli $(100 \mathrm{ml})$ was uniformly spread on the upper surface of plates. Then, three doses of $\mathrm{Cu}$ NPs solution (low, medium and high) were injected in these wells along with control. After 24-h incubation at $37^{\circ} \mathrm{C}$, the inhibition zone diameter around each well for each bacterial plate was measured with great accuracy. The mean and standard deviation (SD) with three replicates was taken for each strain.

\section{Results and Discussion}

To study the stability of $\mathrm{Cu}$ colloidal solution in air, the absorption of $\mathrm{Cu}$ NPs was measured by UV-visible spectroscopy. The absorption band of $\mathrm{Cu}$ NPs has been reported in the range of 400-900 nm [14, 24]. Continuous laser pulses ablate the $\mathrm{Cu}$ target. In liquid environment, the ablated material expands and disperses in many species. Ablated material includes small clusters, nanoparticles, ions and free atoms. For first few pulses, liquid surrounds the ablated plume and $\mathrm{Cu}$ NPs are formed through condensation of molten bubbles or collision of small clusters with free atoms. In liquids, the surface of nanoparticles is charged. Due to the interaction between charged nanoparticles and molecules of liquid environment, an electrical double layer surrounds the NPs surface. The other mechanism is that the NPs provide growing centers for the incoming species. Hence, both mechanisms lead to a broad size distribution of nanoparticles. By increasing the number of laser pulses from 1000 to 1500 , the absorbance increases (along $y$-axis, which shows the concentration of $\mathrm{Cu}$ NPs). The increase in absorbance indicates that the concentration of nanoparticles also increased (more surfaces are available for surface plasmon resonance). UV-visible absorption spectra of $\mathrm{Cu}$ NPs by laser ablation synthesis in solution (LASiS) are shown in Fig. 2. Figure 2 shows the absorption peak at 591 and $589 \mathrm{~nm}$ for 1000 and 1500 shots, respectively, which proves the formation of the Cu NPs in the solution $[12,25]$.

AFM is an important technique for studying the morphology of nanoparticles. Tapping mode of AFM imaging is applied to study $\mathrm{Cu}$ NPs. As mentioned above, during ablation of metal target and plasma formation in liquid environment, many species including free atoms, electrons, small clusters, ions and particles are produced. Silicon substrate was used for AFM analysis. Small particles such as clusters and free atoms impact with existing clusters or

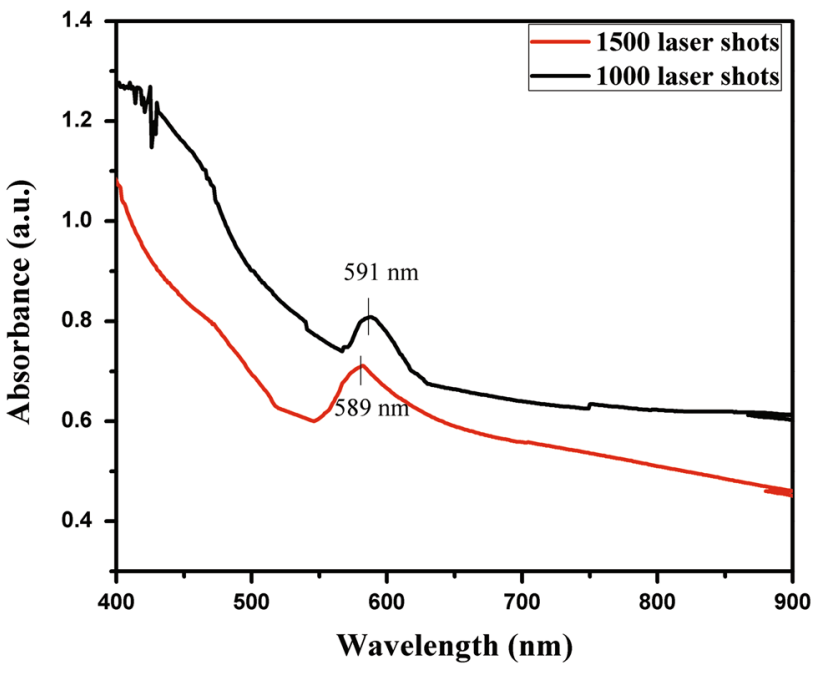

Fig. 2 UV-visible spectra of $\mathrm{Cu}$ NPs fabricated by LASiS

particles, which results in change and growth in size distribution of NPs.

Figure 3 shows an AFM image $(2 \mu \mathrm{m} \times 2 \mu \mathrm{m})$ of $\mathrm{Cu}$ NPs (2D), histogram analysis and 3D image of Cu NPs. The histogram analysis revealed that $\mathrm{Cu}$ NPs (generated by LASiS) have a particle size in the range from 14 to $55 \mathrm{~nm}$. Mean diameter of $\mathrm{Cu}$ NPs is $27 \mathrm{~nm}$ with standard deviation of $4.12 \mathrm{~nm}$.

The crystal structure and phase composition of synthesized $\mathrm{Cu}$ NPs were analyzed by XRD, as shown in Fig. 4 . The diffraction data exhibit that the $\mathrm{Cu}$ NPs have a facecentered cubic (fcc) structure with characteristic diffraction peaks (111), (200) and (220) at $2 \theta$ value of $43.4^{\circ}, 51.1^{\circ}$ and $74.9^{\circ}$, respectively. On the other hand, one diffraction peak was indexed to cuprous oxide $\left(\mathrm{Cu}_{2} \mathrm{O}\right)$ having a corresponding peak (220) at $2 \theta$ value of $60.5^{\circ}$. The presence of $\mathrm{Cu}_{2} \mathrm{O}$ indicates the partial oxidation of $\mathrm{Cu}$ NPs with dissolved oxygen in the solution $[25,26]$. These oxides, which are members of copper compounds family, also attribute to antibacterial mechanism and potential advantage in dental industry. But copper oxide NPs need high concentration to produce bactericidal effect [27].

For $\mathrm{Cu}$ NPs, the oxygen present in the ambient atmosphere rapidly forms an oxide layer on the particle surface when $\mathrm{Cu}$ NPs are exposed to air. However, it seems that these oxides also exhibit antimicrobial properties. This means that $\mathrm{Cu}$ NPs could be synthesized in atmospheric environment, at atmospheric pressure and at room temperature by using deionized water as solvent in the case of present work [26, 28].

Nanoparticles with large surface-to-volume ratio provide more efficient means for antimicrobial activity. The toxicity of $\mathrm{Cu}$ NPs depends on several factors, such as concentration of nanoparticles, size of particle and 
(a)

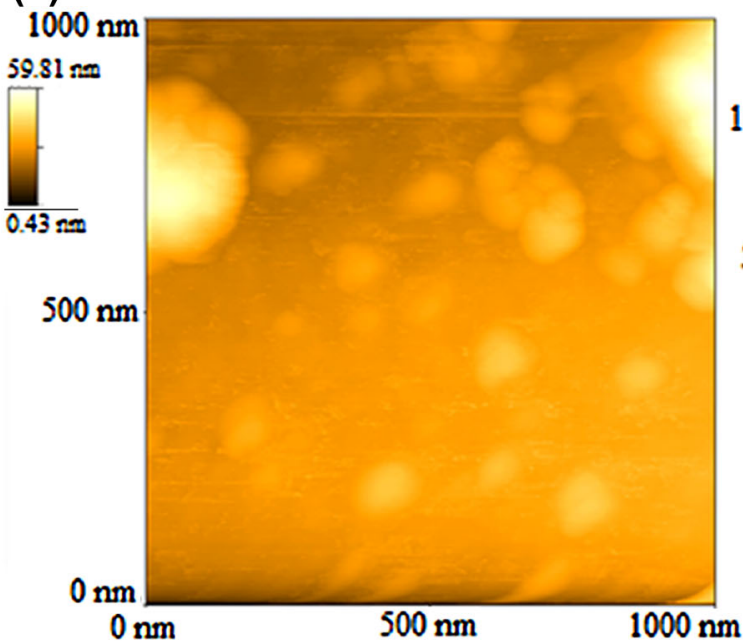

(b)

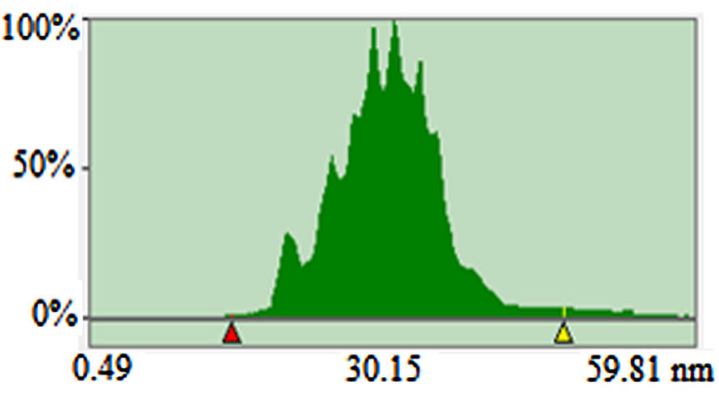

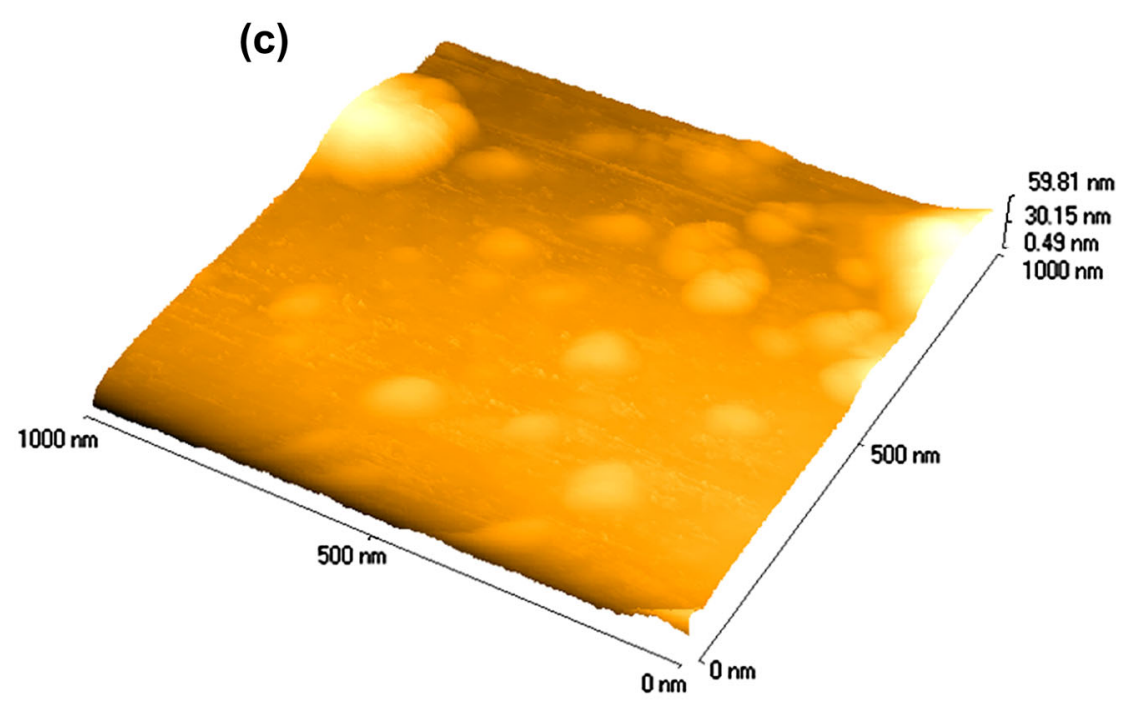

Fig. 3 a 2D AFM image, b histogram and c 3D topographical view of $\mathrm{Cu}$ NPs (fabricated by LASiS), particle size 14-55 nm

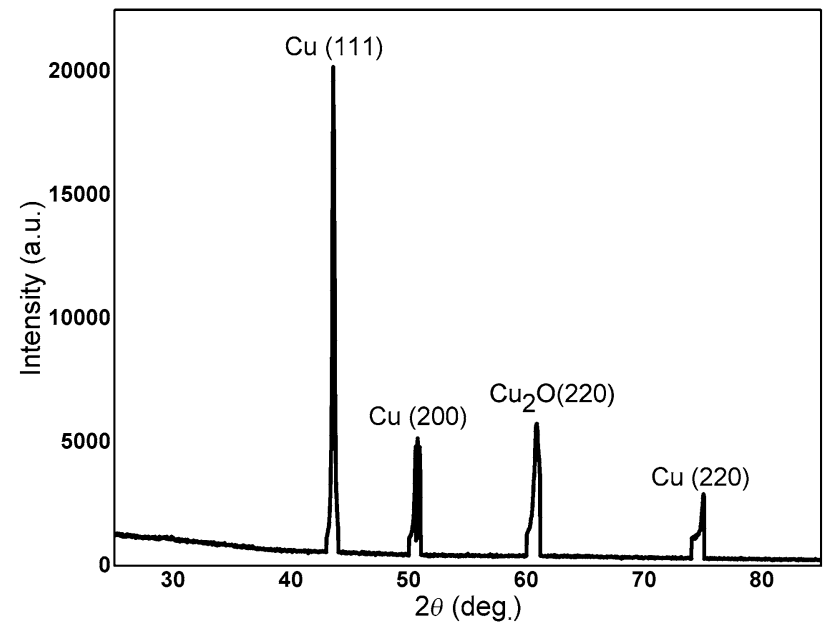

Fig. 4 XRD pattern of the Cu NPs by LASiS concentration of bacteria [21, 25]. The experimental conditions selected were those that yielded best dose-response curve. The antimicrobial activities of $\mathrm{Cu}$ NPs were tested against E. coli (gram-negative strain) and S. aureus (grampositive strain) by turbidity method. Three concentrations of $\mathrm{Cu}$ NPs (generated by LASiS) 19, 39 and $58 \mu \mathrm{mol} / 1$ were used. $\mathrm{Cu}$ NPs with these concentrations inoculated aseptically to the individual test tubes. The inoculated test tubes were incubated at $37^{\circ} \mathrm{C}$ for $24 \mathrm{~h}$. The experiments were carried out in triplicate. The percentage growth and inhibition zone diameter of $E$. coli and $S$. aureus by turbidity and well diffusion method are given in Table 1 . The antimicrobial activity of $\mathrm{Cu}$ NPs fabricated by LASiS, against the both bacterial strains $E$. coli and $S$. aureus, is shown in Fig. 5. 
Table 1 Effects of low, medium, high doses on E. coli and S. aureus

\begin{tabular}{llllll}
\hline $\begin{array}{l}\text { Sr. } \\
\text { no. }\end{array}$ & $\begin{array}{l}\text { Concentration of } \\
\text { nanoparticles }\end{array}$ & $\begin{array}{l}\text { Growth inhibition of } \\
\text { E. coli cells }(\%)\end{array}$ & $\begin{array}{l}\text { Growth inhibition of } S . \\
\text { aureus cells }(\%)\end{array}$ & $\begin{array}{l}\text { Inhibition zone diameter of } \\
\text { E. coli cells (mm) }\end{array}$ & $\begin{array}{l}\text { Inhibition zone diameter of } \\
\text { S. aureus }(\mathrm{mm})\end{array}$ \\
\hline 1 & $19 \mu \mathrm{mol} / 1$ & 52.6 & 60.8 & 16 & 14 \\
2 & $39 \mu \mathrm{mol} / 1$ & 23.7 & 42.5 & 19 & 16 \\
3 & $58 \mu \mathrm{mol} / 1$ & 0.9 & 19.3 & 28 & - \\
4 & $69 \mu \mathrm{mol} / \mathrm{lM}$ & - & 1.3 & & 22 \\
\hline
\end{tabular}

(a)

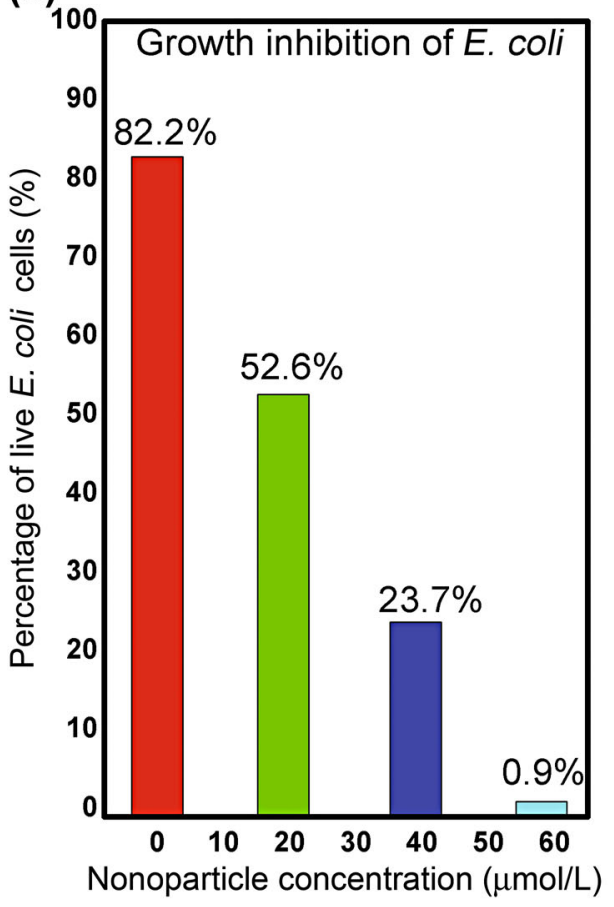

(b)

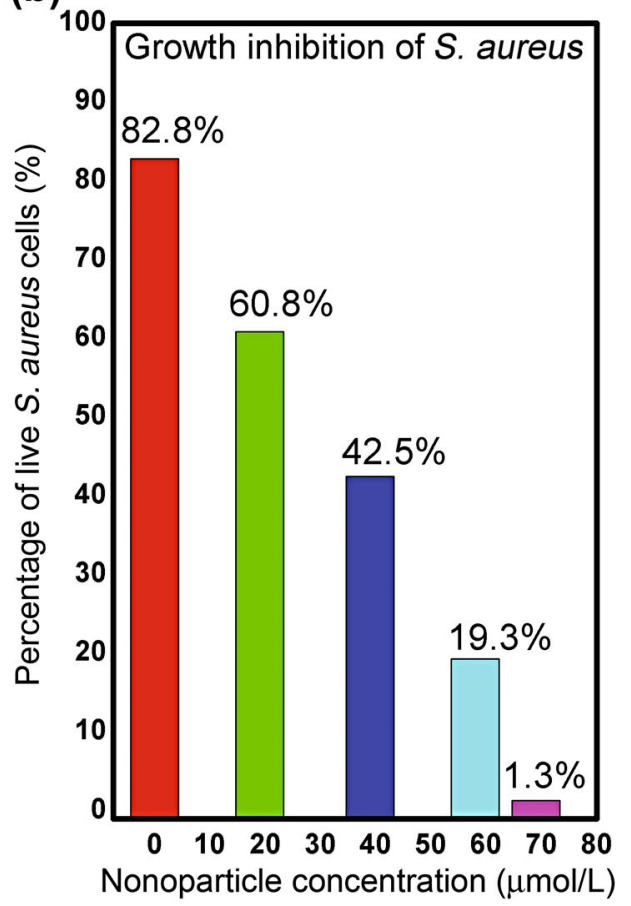

Fig. 5 Graph for growth inhibition of a E. coli, b S. aureus with different concentration of Cu NPs fabricated by LASiS

From experimental results, it is observed that the high dose of $\mathrm{Cu}$ NPs is not enough to completely inhibit the $S$. aureus $(58 \mu \mathrm{mol} / 1$ reduced the bacteria up to $19 \%)$. The concentration of $\mathrm{Cu}$ NPs increases up to $69 \mu \mathrm{mol} / 1$ to maximally inhibit the $S$. aureus (Table 1). It is evident that for both bacteria, the percentage growth decreases as the $\mathrm{Cu}$ NPs concentration increases. The growth inhibition of $E$. coli and $S$. aureus by LASIS-generated nanoparticles is 0.9 and 1.3\%, respectively, as shown in Fig. 5a, b. The clear difference in percentage growth inhibition of both bacterial strains is strongly attributed to the nanoparticles concentration. These outcomes suggest that higher concentration of $\mathrm{Cu}$ NPs is required to inhibit the $S$. aureus than $E$. coli. The zone of inhibition was also measured by well diffusion method. The zone of inhibition for $E$. coli and $S$. aureus with high dose is 28 and $22 \mathrm{~mm}$, respectively
(Table 1). For positive control, no zone of inhibition is observed (Fig. 6).

According to the literature, the better inhibitory effect observed in E. coli than that in $S$. aureus is due to the difference in the outer cell membrane of the bacteria. The gram-negative bacteria at the exterior have a thin layer of lipopolysacchraride and underneath have a thin layer of peptidoglycan (about 7-8 nm). The lipopolysacchraride is composed of covalently linked polysaccharides and lipids, and they lack rigidity and strength. Negative charge on the lipopolysacchraride attracts the $\mathrm{Cu}$ NPs due to positive charges available on particles surface. On the other hand, in gram-positive bacteria, the cell wall is composed of thick layer of peptidoglycan (about 20-80 nm), consisting of polysaccharide linear chains cross-linked by short peptides and forming three-dimensional rigid structures. The 


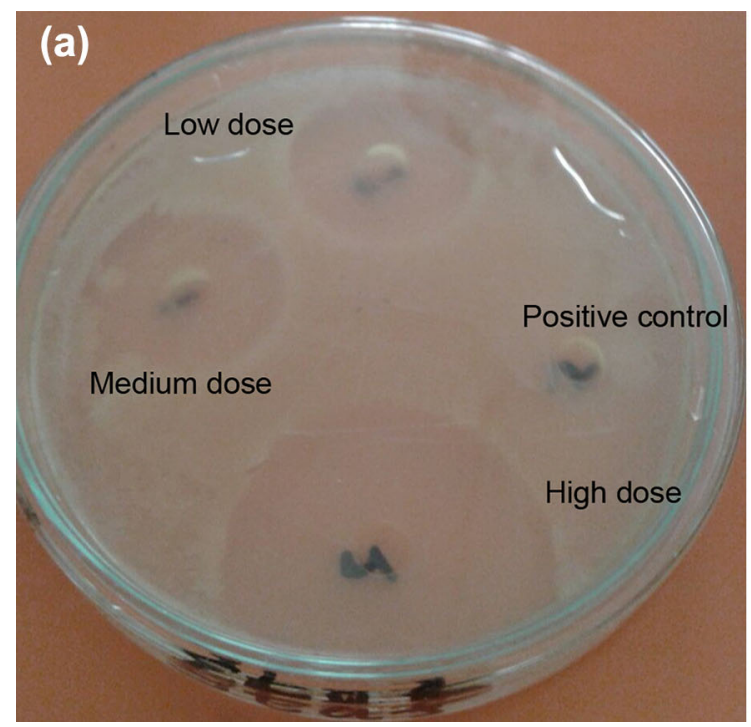

Fig. 6 Diameter of zone of inhibition: a E. coli, b S.aureus bacteria

extended cross-linking and rigidity not only provide the cell wall fewer sites for $\mathrm{Cu}$ NPs, but also make difficult to penetrate the nanoparticles [20]. The bacterial growth inhibition reported in this study strongly depends on the concentration. The observed antibacterial activity of $\mathrm{Cu}$ NPs is due to not only their release of metal ions, but also their morphology, mainly their large ratio of surface to volume, which allows them to directly interact with outer microbial membrane of each bacterium. The mechanism for the antibacterial activity of $\mathrm{Cu}$ NPs is still under debate. One possible explanation is that cell membranes of bacteria containing nano-sized pores can be overcome by the nanoparticles [29].

The presence of nano-sized particles in suspension would ensure continuous release of ions into the nutrient media. $\mathrm{Cu}$ ions released by the nanoparticles attach to the bacterial cell membrane and rupture it, thereby leading to protein denaturation and cell death. The attachment of both nanoparticles and copper ions to the cell membrane causes accumulation of envelope protein precursors, which results in dissipation of the proton motive force. $\mathrm{Cu}$ NPs also exhibit destabilization of the outer membrane and rupture of the plasma membrane, thereby causing depletion of intracellular ATP [29]. $\mathrm{Cu} \mathrm{NPs} \mathrm{and} \mathrm{released} \mathrm{ions} \mathrm{that}$ produce hydroxyl radicals damage or disturb the working of essential proteins and DNA, leading to the cell death $[20,30]$. The significant increase in concentration of nanoparticles leads to higher toxicity and percentage growth of bacteria reduced to minimum values, in comparison with a significant reduction in dose concentration when LASiS method is used for nanoparticles' fabrication. This is due to the fact that Cu NPs fabricated by LASiS method are in pure and colloidal form and the particle size

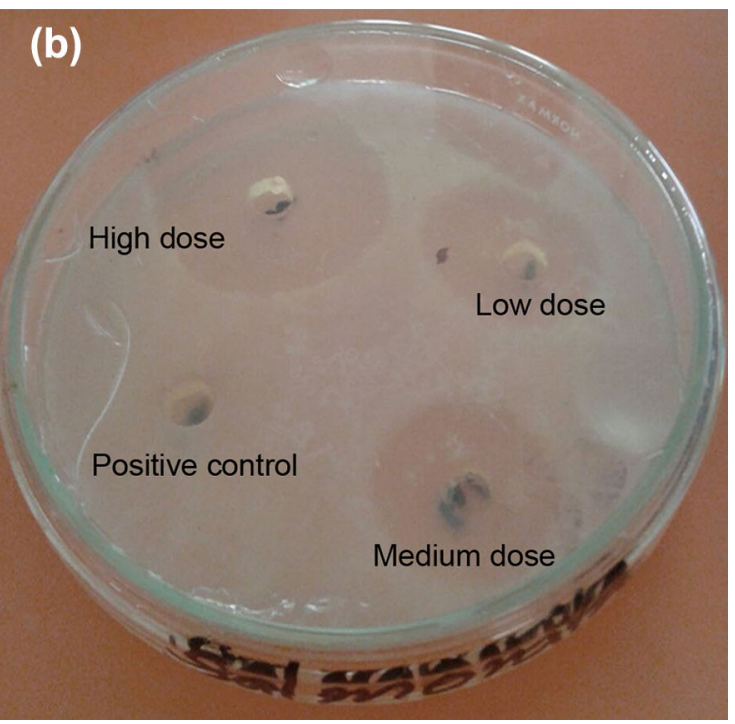

is smaller as compared to nanoparticles produced by chemical reduction method. Khashan et al. [31] measured the zone of inhibition of $\mathrm{CuO}$ with amoxicillin for $E$. coli $((26.0 \pm 1.00) \mathrm{mm})$ with concentration of $1000 \mu \mathrm{g} / \mathrm{ml}$. Ramyadevi et al. [32] calculated zone of inhibition of $S$. aureus $(21 \mathrm{~mm})$ and E. coli $(26 \mathrm{~mm})$.

Yoon and his coworkers also [33] worked on bactericidal effects of copper and silver NPs using strains of E. coli, in which $\mathrm{Cu}$ NPs established superior antibacterial mechanism with respect to silver nanoparticles. It has been reported that limited information about nano-sized $\mathrm{Cu}$ and $\mathrm{CuO}$ was reported previously, although they are much cheaper as compared to silver and can be easily mixed with polymers and have wide application due to its stability with respect to physical and chemical characteristics [34]. While Azam et al. [27] utilized $\mathrm{CuO}$ NPs against various strains and got a result for E. coli $(25 \mathrm{~mm})$ and $S$. aureus $(22 \mathrm{~mm})$, Ruparelia et al. [35] worked on different bacteria with silver and $\mathrm{Cu}$ NPs. They concluded that both had great potential as antimicrobial agent, but copper NPs have extra affinity to the active groups of surface of $B$. Subtillis. In spite of all previous research, our result gave better zone of inhibition for both $S$. aureus $(22 \mathrm{~mm})$ and E. coli $(28 \mathrm{~mm})$.

\section{Conclusion}

In this work, synthesis of copper nanoparticles $(\mathrm{Cu} N \mathrm{NPs})$ has been investigated by laser ablation (LASiS) of bulk copper target in deionized water. The average size range of copper nanoparticle prepared by LASiS was from 14 to $55 \mathrm{~nm}$. The absorption peaks appeared at 591 and $589 \mathrm{~nm}$ for 1000 and 1500 laser pulses, which confirm the 
formation of $\mathrm{Cu}$ NPs. The observed fcc XRD peaks for $\mathrm{Cu}$ NPs are ascribed to the growth along different crystallographic planes. Another phase, cuprous oxide $\left(\mathrm{Cu}_{2} \mathrm{O}\right)$, was also observed, showing the partial oxidation of $\mathrm{Cu}$ NPs with dissolved oxygen in the solution. The antibacterial activity of LASiS-generated $\mathrm{Cu}$ NPs has been investigated against gram-negative Escherichia coli (E. coli) and grampositive Staphylococcus aureus (S. aureus). The results show that the antimicrobial activity of particles depends on the type of microorganism and concentration of nanoparticles. Experimentally, it is observed that more concentration of Cu NPs is required to inhibit S. Aureus than E. coli. This method can be extended for other bimetallic and metallic nanoparticles. Thus, it is concluded that copper and copper oxide nanoparticles are potentially effective against various bacterial pathogens concerned to hospitalrelated infections. They can be another toll for an antibiotic, antifungal and antimicrobial agent in plastics, coatings and textiles industry. In future, main advantage is the fabrication of copper-copper oxide-capped nano-fibrillar cellulose: an efficient new biomaterial.

Acknowledgments The authors gratefully acknowledge the Physics Department of University of Engineering and Technology, Lahore, Physics Department of COMSATS, Lahore, and Chemistry Department of Forman Christian College, A Charted University, Lahore, for accomplishing the AFM and XRD and UV-visible spectrophotometer analysis of the synthesized nanoparticles, respectively. Also the authors are grateful to Department of Microbiology, University of Veterinary and Animal Sciences, Lahore, Pakistan, for the assistance in antibacterial studies.

\section{References}

[1] T. Jumaa, M. Chasib, M.K. Hamid, R. Al Haddad, Nanosci. Nanotechnol. Res. 2, 1 (2014)

[2] W. Yu, H. Xie, L. Chen, Y. Li, C. Zhang, Nanoscale Res. Lett. 4, 465 (2009)

[3] K.S. Tan, K.Y. Cheong, J. Nanopart. Res. 15, 1537 (2013)

[4] H. Hashemipour, M.E. Zadeh, R. Pourakbari, P. Rahimi, Int. J. Phys. Sci. 6, 4331 (2011)

[5] M.M. Miranda, C. Gellini, E. Giorgetti, J. Phys. Chem. 115, $5021(2011)$

[6] A. Umier, S. Naveed, N. Ramzan, M.S. Rafique, Nano Brief Rep. Rev. 7, 1096 (2012)

[7] R. Betancourt-Galindo, P.Y. Reyes-Rodriguez, B.A. PuenteUrbina, C.A. Avila-Orta, O.S. Rodriguez-Fernandez, G. Cadenas-Pliego, R.H. Lira-Saldivar, L.A. Garcia-Cerda, J. Nanomater. 2014, 980545 (2014)
[8] H.X. Zhang, U. Siegert, R. Liu, W.B. Cai, Nanoscale Res. Lett. 4, 705 (2009)

[9] V. Amendola, M. Meneghetti, J. Phys. Chem. Chem. Phys. 11, 3805 (2009)

[10] M. Saito, K. Yasukawa, T. Umeda, Y. Aoi, Opt. Mater. 301, 1201 (2008)

[11] S. Shamaila, H. Wali, R. Sharif, J. Nazir, N. Zafar, Appl. Phys. Lett. 103, 153701 (2013)

[12] R.M. Tilaki, A.I. Zad, S.M. Mahdavi, Appl. Phys. A 88, 415 (2007)

[13] T.M. Al-Nori, J. Sci. 23, 45 (2012)

[14] P. Rahimi, H. Hashemipour, M.E. Zadeh, S. Ghader, Int. J. Nanosci. Nanotechnol. 6, 144 (2010)

[15] S. Kheybari, N. Samadi, S.V. Hosseini, A. Fazeli, M.R. Fazeli, Daru 18, 168 (2010)

[16] B. Duncan, C. Kim, V.M. Rotello, J. Control. Release 148, 122 (2010)

[17] C.R. Patra, R. Bhattacharya, D. Mukhopadhyay, P. Mukherjee, Adv. Drug Deliv. Rev. 62, 346 (2010)

[18] M.G. Guzman, J. Dille, S. Godet, Proc. World Acad. Sci. Eng. Technol. 45, 367 (2008)

[19] A.D. Russell, W.B. Hogo, G.A.J. Ayliffe, Principles and Practice of Disinfection, Preservation and Sterlization, 3rd edn. (Blackwell Scientific Ltd, Oxford, 1999)

[20] F.R. Lourenco, T.J.A. Pinto, Brazil. J. Pharm. Sci. 47, 573 (2011)

[21] B.P. Rama, P.S. Prajna, P.M. Vinita, S. Pavithra, Adv. Bio. Res. 2, 52 (2011)

[22] G. Mishra, S.K. Verma, D. Singh, P.K. Yadawa, R.R. Yadav, Open J. Acoust. 1, 9 (2011)

[23] L. Argueta-Figueroa, R.A. Morales-Luckie, R.J. Scougall-Vilchis, O.F. Olea-Mejía, Prog. Nat. Sci. Mater. Int. 24, 321 (2014)

[24] A.D. Karthik, K. Geetha, J. Appl. Pharm. Sci. 3, 16 (2013)

[25] R. Ali Soomro, S. Hussain Sherazi, N. Memon, M.R. Shah, N.H. Kalwar, K.R. Hallam, A. Shah, Adv. Mater. Lett. 5, 191 (2014)

[26] R. Ramli, M.R. Khan, N.K. Chowdhury, M.D.H. Beg, R.M. Halim, A.A. Aziz, Z. Ibrahim, N.H. Zainal, Adv. Nanopart. 2, 358 (2013)

[27] A. Azam, A.S. Ahmed, M. Oves, M.S. Khan, S.S. Habib, A. Memic, Int. J. Nanomed. 7, 6003 (2012)

[28] K. Giannousi, K. Lafazanis, J. Arvanitidis, A. Pantazaki, S.D. Dendrinou, J. Inorg. Biochem. 133, 24 (2014)

[29] C.P. Jeffrey, Alcamo's Fundamentals of Microbiology, 9th edn. (Jones and Bartlett Publishers, Canada, 2011), pp. 57-85

[30] S. Malathi, V. Ramya, T. Ezhilarasu, T. Abiraman, S. Balasubramanian, J. Nanotechnol. 2014, 1 (2014)

[31] K.S. Khashan, G.M. Sulaiman, F.A. Abdul Ameer, Arab. J. Sci. Eng. 5, 1 (2015)

[32] J. Ramyadevi, K. Jeyasubramanian, A. Marikani, G. Rajakumar, A.A. Rehman, Mater. Lett. 71, 114 (2012)

[33] K. Yoon, J.H. Byeon, J. Park, J. Hwang, Sci. Total Environ. 373, $572(2007)$

[34] J.F. Xu, W. Ji, Z.X. Shen, S.H. Tang, X.R. Ye, D.Z. Jia, X.Q. Xin, J. Solid State Chem. 147, 516 (1999)

[35] J.P. Ruparelia, A.K. Chatterjee, S.P. Duttagupta, S. Mukherji, Acta Biomater. 4, 707 (2008) 